\title{
Dignidade: condição humana compartilhada
}

- Dignity: shared human condition

\section{Helena Esser dos Reis ${ }^{1}$}

\author{
Quanto vale o homem? \\ Menos, mais que o peso? \\ Hoje mais que ontem? \\ Vale menos, velho? \\ Vale menos, morto? \\ Menos um que outro, \\ se o valor do homem \\ é medida de homem? \\ ..................
}

Carlos Drummond de Andrade Especulações em torno da palavra homem

Resumo: O presente artigo visa discutir avanços e recuos no processo histórico de construção da ideia de dignidade humana, a fim de contribuir com o dossiê "Ciência e política: diálogos sobre a dignidade humana em tempo de pandemia". Nossa abordagem será filosófica e partirá da concepção de dignidade humana como valor da pessoa. Com base no pensamento jusnauralista moderno, investigaremos o indivíduo livre e igual do estado de natureza buscando compreender a tensão entre singularidade e individualismo que, embora presente nesta na concepção de indivíduo, aprofunda-se no séc. XIX. Discutiremos, então, a relação com o outro (indivíduo e comunidade) a fim de evidenciar que a aniquilação de vínculos comuns tende a conduzir as pessoas a condições sociais e políticas de subordinação e opressão. O problema que se põe, então, a ser investigado é o re-

1 Doutora em Filosofia pela Universidade de São Paulo. Professora Titular na Universidade Federal de Goiás. Bolsista Produtividade CNPq. helenaesser@ufg.br. 
estabelecimento dos vínculos. Rousseau e Tocqueville encontram na empatia em vista do sofrimento da outra pessoa o caminho contraporem-se à corrosão dos vínculos. O respeito à dignidade humana como uma condição compartilhada emerge junto com a solidariedade.

Palavras-chave: Indivíduo. Singularidade. Individualismo. Solidariedade. Dignidade humana.

\begin{abstract}
This article aims to discuss the advances and retreats in the historical process of building the idea of human dignity, in order to contribute with the dossier "Science and politics: dialogues on human dignity in pandemic times". We will use a philosophical approach that starts in the idea of human dignity as one's value. Based on the modern jusnaturalism thinking, we will investigate the state of nature of the free and equal individual, pursuing to understand the tension between singularity and individualism that, although is present in the idea of the individual, deepens in the 19th century. Then, we will discuss the relationship with the other (individual and community) in order to show that the annihilation of common attachments tends to drive people to social and political conditions of subordination and oppression. So, the problem that is being investigated is the reestablishment of attachments. Rousseau and Tocqueville find in the empathy towards the suffering of the other the path, opposing to the extinction of the attachments. The respect to human dignity as a shared condition emerges together with solidarity.
\end{abstract}

Keywords: Individual. Singularity. Individualism. Solidarity. Human dignity.

A pergunta de Drummond nos leva para o centro de um grave problema filosófico: o valor da pessoa humana. Menos do que investigar o desenvolvimento deste problema na história da filosofia, interessa-me aqui toma-lo já na sua forma elaborada na modernidade para discutir suas repercussões e buscar contribuir com o diálogo sobre a dignidade humana neste tempo de pandemia.

Até a aurora da modernidade a noção de dignidade vinculava-se a uma distinção especial de alguns em relaçãox aos demais. Tal distinção era atribuída a um mérito especial e transparecia nas altas posições e cargos que Ihe eram destinados, em vista dos quais recebiam honras e deferências ${ }^{2}$. Em-

2 Uma explicação acessível e clara pode ser encontrada em COMPARATO, 2006, p. 478-483. 
bora algo este sentido ainda subsista no mundo contemporâneo ${ }^{3}$, os autores do jusnaturalismo moderno - compreendendo cada pessoa como um indivíduo racional e livre - romperam a cadeia hierárquica ${ }^{4}$ que as prendia a uma posição social e política pré-estabelecida, por meio da qual a dignidade era atribuída a algumas e não a outras.

Para romper com essa cadeia social e política, os jusnaturalistas modernos argumentaram que a natureza não fez ninguém dependente de outrem, nem subordinou quem quer que seja. Naturalmente, em um hipotético estado originário da humanidade, todas as pessoas se encontram em um estado de perfeita liberdade e de igualdade. Decorre, desta condição natural, o direito de preservar sua própria natureza, ou seja: sua vida em condições de liberdade e igualdade com os demais ${ }^{5}$. Essa nova concepção possibilitou que todas as pessoas - diferentes umas das outras em muitos aspectos - pudessem ser consideradas ao mesmo tempo indivíduos singulares (incomparáveis, insubstituíveis) e iguais entre si (sem subordinação); e estendeu a todos os seres humanos a possibilidade de requerer dos demais o respeito à sua própria pessoa, à sua liberdade (independência) e aos seus direitos inerentes ou naturais. Enraíza-se aqui uma nova e abrangente concepção de dignidade da pessoa humana, que já não mais supõe distinções, mas igualdade. Todos os seres humanos, iguais por natureza ${ }^{6}$, tornam-se merecedores de respeito ${ }^{7}$.

Assim, a dignidade adquire uma dimensão ontológica, torna-se inerente ao ser humano. Na Fundamentação da Metafísica dos Costumes, Kant (1980) ressalta essa dimensão da dignidade da pessoa na medida em que a compreende como "fim em si mesma" ou com "valor absoluto" (p. 134). Este valor irretorquível de cada pessoa impede qualquer relação de equivalência sendo, portanto, impossível intercambiar uma por outra: "quando uma coisa tem preço, pode-se por em vez dela qualquer outra coisa como equivalente; mas quando uma coisa está acima de todo o preço, portanto não permite

3 Ainda hoje admite-se dizer que pessoas exercendo altos cargos (civis, políticos, militares, eclesiásticos) recebem uma dignidade especial, a qual transparece em certos privilégios e protocolos decorrentes da função.

4 As sociedades aristocráticas caracterizavam-se tanto pela desigualdade entre nobres e plebeus, quanto por uma longa cadeia de relações sociais e políticas hierárquicas que os ligava permanentemente. Uns na condição de senhor, outros na de servos. "Nas sociedades aristocráticas, a classe que dirige a opinião e conduz os negócios, situada de maneira permanente e hereditária acima da multidão, [...]” (TOCQUEVILLE, 1977, p. 347)

5 Veja, por exemplo, Locke. Segundo Tratado sobre o Governo. Cap. 2; Hobbes. Leviatã, Cap. 13 e 14.

6 A noção de igualdade natural dos jusnaturalistas não significa igualdade absoluta entre as pessoas, mas que ninguém está naturalmente subordinado a outrem: "criaturas da mesma espécie e da mesma ordem, nascidas promiscuamente, a todas as mesmas vantagens da natureza e ao uso das mesmas faculdades, terão também de ser iguais umas às outras sem subordinação ou sujeição" (LOCKE, 1978, p. 35)

7 Locke deriva da igualdade o dever de justiça e caridade; Hobbes deriva o temor de uns aos outros, que também pode ser entendido como uma forma avessa do respeito ao outro. 
equivalente, então ela tem dignidade" (p. 140). A ausência de um equivalente intercambiável tem como consequência direta o respeito. É por reconhecer a dignidade inerente a cada pessoa que se deve agir com respeito em relação a si mesmo e a cada um dos demais.

Sem usar a linguagem da dignidade, mas a da natureza humana, a Declaração dos Direitos do Homem e do Cidadão de 1789"reconhece e declara" a liberdade e a igualdade de direitos entre as pessoas visando, com este ato, "lembrar a todos os seus direitos e deveres" tanto nas relações com as outras pessoas como em relação às instituições do Estado. A nova concepção de humanidade a ser reconhecida e preservada estabelece, como finalidade da ordem jurídico-estatal, segundo os jusnaturalistas, a preservação dos direitos naturais dos indivíduos ${ }^{8}$.

Como vai o homem junto de outro homem, sem perder o nome?

Supondo, então, a inexistência de vínculos ou de hierarquias permanentes entre as pessoas, os jusnaturalistas as tornam todas independentes uma das outras e iguais entre si. Essa igualdade inerente diz respeito às "faculdades do corpo e do espírito". Segundo Hobbes (1979), a natureza encarregou-se de produzir a igualdade de tal sorte que,

embora por vezes se encontre um homem manifestamente mais forte de corpo, ou de espírito mais vivo que outro, mesmo assim, quando se considera tudo isso em conjunto, a diferença entre um e outro homem não é suficientemente considerável para que qualquer um possa com base nela reclamar qualquer benefício a que outro não possa também aspirar, tal como ele. (p. 74)

Desta igualdade Hobbes deriva, em primeiro lugar, a capacidade e a esperança de cada um atingir seus próprios fins e, em segundo lugar a desconfiança de uns em relação aos outros na medida em que consideram que os fins (uma casa, comida, trabalho, conforto,...) assemelham-se e o universo de possibilidades é limitado. A garantia do direito natural à vida é frequentemente ameaçada pela presença e pela cobiça do outro. É assim que o temor de uma vida miserável e insegura leva as pessoas, por um cálculo de vantagens, a pactuar entre si dando origem a um Estado Civil, cuja função é criar leis, procedimentos, juízes, polícia que garantam a segurança comum protegendo uns em relação aos outros (bem como em relação aos estrangeiros) e assegu-

8 Segundo Locke: “[...] não é sem razão que [o individuo] procura de boa vontade juntar-se em sociedade com outros que já estão unidos ou pretendem unir-se, para mutua conservação da vida, da liberdade e dos bens, a que chamo de 'propriedade"'. (1978, p. 82) 
rando a cada um o gozo do seu direito natural à vida.

Locke (1978), afirmando o valor individual e os direitos inerentes a estes indivíduos, imagina que o Estado Civil tenha origem em um pacto realizado entre indivíduos em vista da "mútua conservação da vida, da liberdade e dos bens" (p. 82). Embora o pacto dê origem a uma comunidade, que detêm o poder legislativo, Locke afirma que o exercício do direito político de legislar pode ser delegado possibilitando, deste modo, que os indivíduos, agora tornados cidadãos, obtenham a proteção civil aos seus direitos sem, contudo, precisarem se ocupar das decisões e ações políticas.

Os direitos naturais, ao serem considerados inerentes à natureza humana e, portanto, irrevogáveis para cada indivíduo, adquirem o sentido de proteção das pessoas umas em relação às outras e contra os poderes do Estado. Neste sentido, Locke chega a admitir o direito de rebelião ou de resistência contra o governo que viole os direitos naturais dos indivíduos. Mesmo Hobbes, embora não imponha obrigações ao soberano, admite, pelo menos, que há limites à obediência dos súditos. No capítulo XXI do Leviatãa, ao tratar da liberdade, Hobbes ressalta que há uma "verdadeira liberdade dos súditos", a qual diz respeito àquelas coisas que "embora ordenadas pelo soberano, não obstante eles [os súditos] podem sem injustiça recusar-se a fazer" (p. 132).

Concepções semelhantes às de Hobbes e Locke são formuladas ao longo dos séculos XVII e XVIII ressaltando o valor inerente de indivíduo e, ao mesmo tempo a primazia do indivíduo em relação à comunidade. A potência destas ideias aparece nas grandes transformações culturais, econômicas, sociais, civis e políticas que marcam a passagem das sociedades aristocráticas fundamentadas na desigualdade social e na opressão política, que prevalecia até então em toda Europa, para as sociedades democráticas baseadas na igualdade de condições e na soberania do povo.

Rousseau (1978), contrariamente a Hobbes e Locke, opõe-se a este fechamento do indivíduo sobre si mesmo; não abre mão do exercício do poder legislativo pelo corpo do povo: "só àqueles que se associam cabe regulamentar as condições da sociedade" (p. 55). É claro que tal exigência traz problemas práticos facilmente perceptíveis, entretanto ressalta um forte vínculo entre o indivíduo e a comunidade que resguarda o compromisso fundamental de cada cidadão com os demais e com a comunidade política. Entretanto, já no final do séc. XVIII, os liberais doutrinários franceses acusaram Rousseau de aniquilar a vontade individual, de submeter o indivíduo ao todo. Benjamin Constant (1985), quase se desculpando "deste gênio sublime que era anima-

9 Veja também, em HOBBES, Do cidadão (São Paulo, Martins Fontes, 1992). Parte II, cap. 6, parágrafo 13: Que o poder que seus cidadãos lhe concederam é absoluto, e qual medida de obediência eles lhe devem. 
do pelo mais puro amor à liberdade", afirma que, por meio do exercício do poder legislativo diretamente pelo corpo do povo, Rousseau "forneceu desastrosos pretextos a mais de um tipo de tirania" (p. 16). Para estes doutrinários, a delegação das atribuições políticas dos cidadãos a representantes é também uma forma de preservar a liberdade ou "o exercício pacífico da independência privada" (p. 14). Segundo Constant, a "liberdade dos modernos" se caracteriza fundamentalmente pela afirmação do indivíduo frente ao todo social por meio da proteção legal aos seus direitos civis. Contudo, semelhante afirmação individual carrega consigo a tendência a separar o indivíduo da comunidade e abre caminho para o individualismo.

Como pode o homem sentir-se a si mesmo, quando o mundo some?

Ao arrancar o indivíduo da comunidade para sustentar uma concepção de igual valor ou igual dignidade de todas as pessoas, o jusnaturalismo moderno cria um novo problema: nesta nova sociedade de indivíduos iguais entre si, à revelia de suas particularidades, nada os une. A fantasia do estado de natureza, no qual as pessoas vivem isoladamente, retira delas a responsabilidade para com o outro, para com o cuidado necessário à sobrevivência de cada um e da espécie . ${ }^{10} \mathrm{O}$ pacto de associação de cada um com cada um transporta para dentro da comunidade política a mesma fantasia, a coletividade não passa de um conjunto de indivíduos justapostos, uma multidão ou aglomeração" ${ }^{11}$.

O indivíduo, agora tornado cidadão, não é sensível a pautas comuns, permanece, no âmbito político, voltado aos seus próprios interesses particulares. De acordo com Tocqueville (1977), nesta sociedade de pessoas consideradas iguais entre si, mas desvinculadas umas das outras, os indivíduos já não se lembram de

10 A ficção do "estado de natureza" supõe que as pessoas possam viver isoladamente, de modo que mesmo as famílias não perduram. Rousseau expressa esta ideia com grande clareza: "nesse estado primitivo, não tendo nem casas, nem cabanas, nem propriedades de qualquer espécie, cada um se abrigava em qualquer lugar e, frequentemente por uma única noite, os machos e as fêmeas uniam-se fortuitamente segundo o acaso, a ocasião e o desejo [...] e separavam-se com a mesma facilidade. A mãe a princípio aleitava seus filhos devido à própria necessidade; depois, tendo o hábito lhos tornado caros, alimentava-os por causa da necessidade deles. Os filhos, assim que tinham forças para buscar o pasto, não tardavam a abandonar a própria mãe e, como quase não havia outro meio de encontraremse senão o de não perderem-se de vista, logo encontravam-se em situação de nem sequer se reconhecerem uns aos outros." (ROUSSEAU. Discurso sobre a origem e os fundamentos da desigualdade entre os homens. São Paulo. Abril Cultural, 1978. Coleção Os Pensadores. p. 247. )

11 Em oposição a esta concepção, Rousseau afirma, no Contrato Social, haver muita diferença entre "subjugar uma multidão e reger uma sociedade. Sejam homens isolados, quantos possam ser submetidos a um só, e não verei nisso senão um senhor e escravos, de modo algum considero-os um povo e seu chefe. Trata-se, caso se queira, de uma agregação, mas não de uma associação, nela não existe nem bem público, nem corpo político" (ROUSSEAU, 1987, p. 30). 
seus antepassados, nem se projetam em seus descendentes; sentem-se descomprometidos uns com os outros, indiferentes, quase estranhos entre si. Imaginam que tudo o que cada um é e tudo o que cada um tem, não devem a ninguém, senão a si próprio. Semelhante situação social propicia que cada um faça uma imagem muito grande e positiva de si mesmo, ao mesmo tempo em que relega para segundo plano a imagem do outro. Imaginando que "seu destino inteiro está entre as suas mãos" (p. 387), acredita bastar-se a si mesmo. É nesta situação que surge um novo sentimento, o qual Tocqueville nomeia como individualismo. Este, diferente do egoísmo (um instinto cego do indivíduo), é descrito como ausência de virtudes públicas, uma doença do espírito público ${ }^{12}$, posto que é um sentimento refletido e pacífico que procede, não de um sentimento depravado, mas da ilusão de cada um bastar-se a si mesmo.

A existência emsimesmada destes indivíduos os afasta uns dos outros. Para Tocqueville (1977) esta vida vivida privadamente avilta as pessoas, rouba delas a capacidade de desenvolverem-se como seres humanos:"os sentimentos e as ideias não se renovam, o coração não cresce e o espírito não se desenvolve senão pela ação recíproca dos homens uns com os outros" (p. 393).

A reunião destes indivíduos já não forma uma comunidade, mas apenas uma multidão ${ }^{13}$; cada qual voltado sobre si mesmo e saciado por"pequenos e vulgares prazeres" torna-se um estranho em sua comunidade: "[...] seus filhos, seus amigos, constituem para ele toda a espécie humana; quanto ao restante de seus concidadãos, está ao lado deles, mas não os vê; toca-os e não os sente, existe apenas em si e para si mesmo [...]" (p. 531)

Estranhos uns aos outros, os indivíduos já não percebem qualquer relação entre os seus próprios interesses e os interesses coletivos; desejam a proteção do Estado para o gozo tranquilo de seu bem-estar, mas negam-se a compartilhar a responsabilidade sobre o que diz respeito à coletividade como um todo. A indiferença política faz com que, voluntariamente, deixem escapar seus direitos políticos tornando-se, deste modo, "um rebanho de animais tímidos e industriosos do qual o governo é o pastor" (p. 532). Nestas circunstâncias, afirma Tocqueville, a soberania do povo foi usurpada com o consentimento dos próprios indivíduos, os quais se satisfazem em obedecer a um poder tutelar desde que o governante lhes ofereça a tranquilidade necessária para gozarem dos benefícios privados. Essa tutela despótica do governo central "tira dos cidadãos qualquer paixão em comum, qualquer necessidade mútua, qualquer

12 "Doença do espírito público" é uma expressão usada Lamberti para referir-se ao individualismo caracterizado por Tocqueville como um fenômeno social e político. Veja: LAMBERTI. 1970. p. 12.

13 Multidão é a palavra usada por Tocqueville para descrever o conjunto formado por "homens semelhantes e iguais, que sem descanso se voltam sobre si mesmos, à procura de pequenos e vulgares prazeres [...]” (1977, p. 531). Tanto a palavra, quanto o contexto, remete à crítica feita por Rousseau aos autores do jusnaturalismo, que não distinguem a mera aglomeração de indivíduos em vista de seus interesses privados, da constituição de uma comunidade política. 
obrigação de se entenderem, qualquer ocasião de agirem juntos; por assim dizer, os empareda na vida privada" (TOCQUEVILLE, 2009, p. XLVIII).

Seja nas sociedades imaginadas pelos autores jusnaturalistas, na qual o indivíduo se constitui como sujeito de direito anteriormente à sociedade, seja na sociedade democrática degradada, pensada por Tocqueville, o papel mediador do outro é desconhecido. Os vínculos entre indivíduos já não são imediatos, dependem das leis e regras estabelecidas. O reconhecimento de que todos os seres humanos são merecedores de igual respeito aparece, na melhor das hipóteses, como um princípio formal, cujo efeito é fortemente nuançado em vista das regulamentações civis, sociais, econômicas, políticas, culturais que tem sempre na figura do indivíduo o seu destinatário primeiro. A intermediação procedimental entre as pessoas, as impede de espontaneamente colocarem-se umas no lugar das outras e vincularem-se.

\section{Mas que dor é homem? Homem como pode descobrir que dói?}

Se o processo de individuação, que estende a dignidade a todas as pessoas e faculta a expressão da singularidade de cada uma, traz consigo o individualismo separando umas das outras, cabe perguntar: como respeitar a dignidade das pessoas quando a perspectiva de cada uma exclui a da outra? Se as pessoas foram tornadas indivíduos, que se relacionam com o outro e com o mundo tendo em vista seus próprios interesses, a reconstrução do comum, do comunitário, que envolvam compromissos recíprocos, parece requerer que reconheçam suas semelhanças, que rompam com o mundo restrito ao eu e que se projetem para além de si mesmo.

Não há concessões nem meias palavras em Rousseau e Tocqueville quando se trata de integrar o indivíduo à comunidade. "Mudar a natureza humana"14 e "arrancados da observação de si mesmos"15 são as palavras - nada sutis - com as quais estes autores expressam a necessidade de construção

14 "Aquele que ousa empreender a instituição de um povo deve sentir-se com capacidade para, assim dizer, mudar a natureza humana, transformar cada indivíduo, que por si mesmo é um todo perfeito e solitário, em parte de um todo maior, do qual de certo modo esse indivíduo recebe sua vida e seu ser; alterar a constituição do homem para fortificá-la; substituir a existência física e independente que todos nós recebemos da natureza, por uma existência parcial e moral" (ROUSSEAU, 1978, p. 57 - grifo meu)

15 "Quando os cidadãos são forçados a ocupar-se dos negócios públicos, são necessariamente tirados do meio de seus interesses individuais e arrancados, de tempos em tempos, à observação de si mesmos. A partir do momento em que tratam em comum dos assuntos comuns, cada homem percebe que não é tão independente de seus semelhantes como imaginava a princípio e, para obter o seu apoio, muitas vezes é necessário emprestar-lhes o seu concurso." (TOCQUEVILLE, 1977, p. 389 - grifo meu). 
de vínculos interpessoais e comunitários. Ainda que em certa medida estes vínculos possam se estabelecer artificialmente, por meio de instituições e leis que aproximem as pessoas, segundo argumenta Rousseau, "ninguém se torna sensível a não ser quando sua imaginação se excita e começa a transportá-lo para fora de si" (ROUSSEAU, 1999, p. 289). Ou seja, instituições e leis são insuficientes sem que haja sensibilidade, sentimentos de humanidade, que faça com que as pessoas se coloquem imediatamente no lugar umas as outras.

Em Emílio, ao introduzir o tema da piedade (ou comiseração) ${ }^{16}$, Rousseau (1999) apresenta algumas perguntas e respostas provocantes:

Por que os reis são impiedosos para com os súditos? É porque têm certeza de que nunca serão homens. Por que os ricos são tão duros para com os pobres? É porque não tem medo de empobrecer. Por que a nobreza tem tamanho desprezo pelo povo? É porque um nobre nunca será um plebeu... (p. 291)

A ironia das questões demonstra que a ausência de condições comuns e compartilhadas impede que as pessoas possam se reconhecer como seres iguais, afetados de modo muito semelhante. A crença individualista de que cada um basta a si mesmo produziu, para cada indivíduo, a noção equivocada de que a sorte dos demais não tem nenhuma relação consigo mesmo. Romper com este equívoco depende, em acordo com os argumentos de Rousseau, da capacidade de os indivíduos sentirem que compartilham algo em comum, de identificarem-se uns com os outros, de colocarem-se no lugar do outro e sentirem-se afetados pelas mesmas vicissitudes. Segundo Rousseau (1999), "só lamentamos no outro os males de que não nos acreditamos isentos" (p. 291).

Para que isso aconteça, segue o autor, é preciso que as pessoas sejam capazes de compartilhar o sofrimento ${ }^{17}$. É preciso que percebam que as pessoas sofrem, sentem dores, muitas vezes as mesmas dores, mas nem sempre. Nem sempre experiência do sofrimento precisa ser a mesma para que as pes-

16 Por meio do que Rousseau denomina piedade, um sentimento natural, as pessoas abrem-se para as outras e para os demais seres sensíveis com os quais se identificam, pois a visão do que falta (viola) às relações humanas é sempre mais clara do que a maneira correta de organizá-las. Entretanto, o tema da piedade traz dificuldades para os estudiosos do pensamento de Rousseau em vista de pequenas diferenças de abordagem de uma obra para outra. Sugiro, portanto, para uma compreensão ampla e profunda, a interpretação cuidadosa de GOLDSCHMIDT (1983).

17 Em diferentes obras, Rousseau afirma que a expansão do indivíduo em direção ao outro não decorre do júbilo, mas do sofrimento ou dor, da visão acerca do que falta (viola) às pessoas. Em Discurso sobre a origem e fundamentos da desigualdade entre os homens, o autor introduz o sentimento de piedade como uma "repugnância inata de ver sofrer o seu semelhante" (1978, p. 253). Em Emílio, o sentimento de piedade aparece como "o primeiro sentimento relativo que toca o coração humano conforme a ordem da natureza”, mas para que este sentimento surja é preciso saber que "existem seres semelhantes que ela que sofrem o que ela sofreu, que sentem as dores que ela sentiu e outras que tem ideia de que também poderá sofrer. De fato, como nos deixaremos comover pela piedade, a não ser saindo de nós mesmos e identificando-nos com o animal que sofre e deixando, por assim dizer, nosso ser para assumir o seu? (ROUSSEAU, 1999, p. 289). 
soas se reconheçam na dor da outra. A imaginação é capaz de projetar cada uma na dor da outra e fazê-la sofrer junto.

Em um período cujas relações econômicas, sociais, culturais, civis e políticas estavam construídas sobre a escravidão, a desigualdade, subordinação, a subserviência e a opressão, Tocqueville parece compartilhar as ideias de Rousseau. No último capítulo do primeiro tomo de A democracia na América, tratando da situação dos índios e negros nos Estados Unidos, ele afirma que, ao sul, "a raça inteira dos brancos formava um corpo aristocrático" (TOCQUEVILLE, 1977, p. 267) absolutamente afastada dos negros. A palavra "aristocrático", utilizada por ele, nessa obra, no contexto do país que - segundo seu julgamento - melhor realiza a democracia no séc. XIX, não é à toa; ressalta a desigualdade e a opressão aí posta. Ele entende que

\section{Num povo aristocrático, cada casta tem as suas opiniões, os seus sentimentos, os seus direitos, os seus costumes, a sua existência a parte. Assim, os homens que a compõem nunca se parecem a todos os outros, nunca tem a mesma maneira de pensar e de sentir, e mal chegam a crer que fazem parte da mesma humanidade. (p. 427)}

Entre brancos e negros nada os assemelhava. E, desde que a escravidão foi abolida e trabalhadores livres de outras regiões do país ou mesmo da Europa passaram a ocupar-se das tarefas antes destinadas aos negros, estes tornaram-se invisíveis aos brancos e ao Estado. Se a escravidão saiu das leis, permaneceu nos costumes. O preconceito é uma face do individualismo que aí se introduz nos costumes, nas relações interpessoais e comunitárias. Reforça a separação entre as pessoas e a abre caminho para toda forma de discriminação. Tocqueville (1977), denunciando a "violação de todos os direitos da humanidade" (p. 278), cometida pelos brancos contra os negros nos Estados Unidos, no início do séc. XIX, admite que a abolição da escravidão naquele país foi apenas "um meio de retardar a luta das duas raças" (p. 276).

Para além de qualquer lei ou regra, a percepção de semelhança e os compromissos recíprocos advêm, segundo Rousseau e Tocqueville, por meio da comiseração em face ao sofrimento de outra pessoa; do sentimento de que há algo de interpessoal, de compartilhado, na miséria de quem quer que seja. Os revezes afetam as pessoas corroendo a soberba individual e as vinculam. São as vicissitudes da vida, o infortúnio, a atribulação, que, expondo a fragilidade de cada uma, a necessidade do cuidado da outra, tornam as pessoas dispostas ao acolhimento, à solidariedade. A necessidade umas das outras está ligada ao que há de comum no viver juntos; portanto, não se trata de beneficência ou ajuda à outra pessoa, mas de reciprocidade. A pessoa afetada pelo sofrimento da outra, ao expandir-se ou solidarizar-se com esta adquire clareza acerca da própria fragilidade, da necessidade do outro, da singularida- 
de de cada pessoa, da falta que uma faz a outra.

A experiência, quase surreal da Covid-19, ainda que vivida diferentemente por cada uma das pessoas, é uma experiência que atravessa a todas conectando umas as outras. Seja na árdua luta dos profissionais da saúde, no compartilhamento de pesquisas de vacinas e remédios, na manutenção dos serviços básicos para a população, nas ajudas humanitárias aos mais vulneráveis e necessitados, no cumprimento do isolamento social, nos shows dos artistas - amadores e profissionais - pelas varandas e internet, nas manifestações de pêsames e solidariedade às tantas vidas perdidas..., as pessoas parecem reencontrar a humanidade, redescobrir a importância de cada um e de cada uma em sua singularidade, ao mesmo tempo em que a dimensão da perda se torna crucial porque irreparável.

Nas ações e manifestações que ocorrem mundo a fora - dos aplausos às equipes de saúde aos protestos contra a má gestão da saúde pública - as pessoas expressam a convicção de que vencer o vírus exige comunidade, solidariedade, ação em comum, respeito às pessoas. O sofrimento compartilhado faz com que as pessoas se responsabilizem umas pelas outras. Cada pessoa clama pela outra, pelo cuidado e por sua ação responsável. A ética da alteridade $^{18}$ reverbera, contemporaneamente, críticas ao individualismo (que não para de crescer no mundo atual) semelhantes às de Rousseau e Tocqueville. Tomando a perspectiva do outro, por meio da injunção daquele que sofre, busca reestabelecer o vínculo entre as pessoas: "Um rosto que sofre emite um comando, um decreto de performance específica: 'Não me mate', 'Receba-me bem,', Dê-me abrigo',' Dê-me o que comer"'(DOUZINAS, 2009, p. 355). A esta súplica que interpela de modo "pessoal, concreto e direto", a única resposta possível é o respeito imediato à outra pessoa.

Como quer o homem ser destino, fonte? Que milagre é o homem? Que sonho, que sombra?

Para impedir o crescimento do individualismo e resgatar o respeito à

18 No século XX estrutura-se uma corrente de pensamento ético, que ficou conhecida como ética da alteridade, a qual parte do suposto da diferença e da interdependência existente entre as pessoas, que convoca à responsabilização de uma em relação às outra. A alteridade, segundo Ruiz, "oferece critérios e referências para construir princípios e valores orientadores da prática. Não existe um caminho universal para ser pessoa, não há um padrão único para se viver a existência humana, não existe um único modo de realizar a dignidade humana. A alteridade se abre para a existência humana como oferta plural de possibilidades de ser. O humano tem que ser reinventado a cada dia e em cada sujeito. Contudo o relativismo não é total, existe um limite e uma referência para a prática humana. Esse limite é a destruição do mundo, a degradação ou aniquilamento da vida e negação do outro ser humano. Ou seja, a negação da alteridade" (RUIZ, 2006, p. 218-219). 
dignidade das pessoas, seguindo as pistas de Rousseau e Tocqueville, é preciso, por um lado, desenvolver a sensibilidade que vincula as pessoas umas às outras; é preciso oferecer às pessoas "objetos sobre os quais possa agir a força expansiva de seu coração, que o dilatem, que o estendam sobre os outros seres, que o façam por toda parte achar-se fora de si" (Rousseau, 1999, p. 289). É o sofrimento que traz a possibilidade do milagre.

Se a sensibilidade frente aos sofrimentos e às injustiças faz cada pessoa sair de dentro de si mesma e vincular-se a outra, por outro lado, este vínculo não é unicamente interpessoal. Expande-se, penetra largamente na vida em comum. Para Rousseau e Tocqueville a política não é um espaço de jogo de forças, mas de construção de algo em comum. São idiotai ${ }^{19}$ aqueles que se ocupam, no espaço público, exclusivamente do seu próprio interesse. Por isso, é preciso criar - ainda que artificialmente, afirma Tocqueville (1977) - espaços públicos que estimulem a resolução conjunta dos problemas comuns. É neste sentido que o autor valoriza as todas as formas de associações (civis e políticas) entre os cidadãos dos estados democráticos:

\begin{abstract}
Uma associação política tira, ao mesmo tempo, de seu próprio círculo, uma infinidade de indivíduos; embora sejam naturalmente separados pela idade, pelo espírito, pela fortuna, ela os aproxima e os põe em contato. Eles se encontram uma vez e aprendem a se encontrar sempre [...] Aprendem a submeter a sua vontade à de todos os outros e a subordinar os seus esforços particulares à ação comum, coisas que não é menos necessário saber nas associações civis que nas associações políticas. (p. 398)
\end{abstract}

A cooperação entre os cidadãos assemelha-se à solidariedade entre as pessoas. É em vista do entrelaçamento dos direitos sociais e políticos que cada pessoa e as comunidades podem resistir ao individualismo. Longe de abandonar a singularidade, que faz de cada pessoa um ser individual único, portanto incomparável e insubstituível, repudiar o individualismo (crença de que cada pessoa basta a si mesma) significa, para cada um, resgatar a solidariedade e os vínculos comunitários necessários ao respeito à dignidade humana. A despeito da simplicidade do enunciado, a tarefa, que parece implicar uma reforma nos costumes e nas instituições, é mesmo desmedida. Não encontramos nos filósofos indicações práticas, programas de ação. Suas ideias, contudo, reverberam nas Declarações de Direitos. Tocqueville, embora crítico ferrenho dos excessos revolucionários, encontra já na Declaração dos Direitos do Homem e do Cidadão, de 1798, a salvaguarda da dignidade das pessoas como base comum e recíproca das relações civis, sociais, econômicas, jurídicas e políticas. Nas declarações de direitos, a digni-

19 A palavra idiotai está aqui grafada em grego para chamar atenção ao seu sentido original. Na antiga Grécia, idiota era denominado o cidadão que abdicava de seus compromissos políticos. 
dade humana não é apenas reconhecida como característica ontológica inerente às pessoas, mas torna-se fonte geradora de direitos a serem resguardados pela comunidade humana. Essa mesma ideia pode ser vista no preâmbulo da Declaração Universal dos Direitos Humanos, de 1948, o qual começa afirmando: "Visto que o reconhecimento da dignidade inerente a todos os membros da família humana e de seus direitos iguais e inalienáveis é o fundamento da liberdade, da justiça e da paz no mundo". E, ainda, nos preâmbulos do Pacto Internacional de Direitos Econômicos, Sociais e Culturais e do Pacto Internacional de Direitos Civis e Políticos (ambos de 1966), que expressam o reconhecimento que os direitos iguais e inalienáveis "decorrem da dignidade inerente à pessoa humana".

A dignidade da pessoa, embora resida na singularidade individual que faz cada pessoa incomparável e insubstituível, não é à revelia das demais. A dignidade de uma pessoa supõe a dignidade de todas as outras; precisa ser compartilhada por toda a humanidade. A dura experiência da Covid-19 que estamos vivendo neste momento nos faz perceber que a solidariedade (contrapondo-se ao individualismo), assim como a cooperação (que se opõe ao impedimento e ao prejuízo) são o sentimento e a ação que melhor expressam o respeito pela dignidade de cada pessoa. As experiências do sofrimento produzidas pela pandemia e as muitas demonstrações de acolhimento a outra pessoa, manifestadas na ajuda, no cuidado, na responsabilização de umas pelas outras, trazem esperanças de, pelo menos, minimizar o individualismo contemporâneo. Contudo, nada nos assegura ainda que - passado o momento - humanidade será capaz de perseverar na construção de novas relações entre as pessoas e o mundo comum.

\section{Referências}

COMPARATO, Fábio Konder. Ética: direito, moral e religião no mundo moderno. São Paulo, Cia das Letras, 2006.

CONSTANT, Benjamin. Da liberdade dos antigos comparada a dos modernos. In: MORAES, João Quartim (org.). Filosofia política. Porto Alegre, LPM, 1985.

DECLARAÇÃO DOS DIRETOS DO HOMEM E DO CIDADÃO. Paris, 1789. Disponível em: http://www.direitoshumanos.usp.br/index.php/Documentos-anteriores-\%C3\%A0cria\%C3\%A7\%C3\%A3o-da-Sociedade-das-Na\%C3\%A7\%C3\%B5es-at\%C3\%A9-1919/ declaracao-de-direitos-do-homem-e-do-cidadao-1789.html. Acesso em: 15 ago. 2020.

DECLARAÇÃO UNIVERSAL DOS DIREITOS HUMANOS, ONU, 1948. Disponível em: http://www.direitoshumanos.usp.br/index.php/Table/Sistema-Global.Declara\%C3\%A7\%C3\%B5es-e-Tratados-Internacionais-de-Prote\%C3\%A7\%- 
C3\%A3o/. Acesso em: 15 ago. 2020.

DOUZINAS, Costas. O fim dos direitos humanos. São Leopoldo, UNISINOS, 2009.

HOBBES, Thomas. Leviatã. São Paulo. Abril Cultural, 1979. Coleção Os Pensadores.

HOBBES, Thomas. Do cidadão. São Paulo: Martins Fontes, 1992.

KANT, I. Fundamentação da Metafísica dos Costumes. São Paulo. Abril Cultural, 1980. Coleção Os Pensadores.

LAMBERTI. Jean-Claude. La notion d' invidualisme chez Tocqueville. Paris, PUF, 1970.

LOCKE, John. Segundo tratado sobre o governo. São Paulo. Abril Cultural, 1978. Coleção Os Pensadores.

GOLDSCHMIDT, Victor. Antropologie et politique. Les principes du système de Rousseau. Paris: Vrin, 1983.

PACTO INTERNACIONAL DE DIREITOS CIVIS E POLITICOS, ONU, 1966. Dispónível em: http://www.direitoshumanos.usp.br/index.php/Table/SistemaGlobal.-Declara\%C3\%A7\%C3\%B5es-e-Tratados-Internacionais-de-Prote\%C3\%A7\%C3\%A3o/. Acesso em: 15 ago. 2020.

PACTO INTERNACIONAL DE DIREITOS ECONÔMICOS, SOCIAIS E CULTURAIS. ONU, 1966. Dispónível em: http://www.direitoshumanos.usp.br/index.php/ Table/Sistema-Global.-Declara\%C3\%A7\%C3\%B5es-e-Tratados-Internacionais-de-Prote\%C3\%A7\%C3\%A3o/. Acesso em: 15 ago. 2020.

ROUSSEAU, Jean-Jacques. Emílio. São Paulo: Martins Fontes, 1999.

ROUSSEAU, Jean-Jacques. Do contrato social. São Paulo. Abril Cultural, 1978. Coleção Os Pensadores.

RUIZ, Castor Bartolomé. As encruzilhadas do humanismo. A subjetividade e a alteridade ante os dilemas do poder ético. Petrópolis, Vozes, 2006.

TOCQUEVILLE, Alexis de. A democracia na América. Belo Horizonte, Itatiaia - EDUSP, 1977.

TOCQUEVILLE, Alexis de. O antigo regimee a revolução. São Paulo, Martins Fontes, 2009. 